\title{
Structural, Optical Constants and Photoluminescence of ZnO Thin Films Grown by Sol-Gel Spin Coating
}

\author{
Abdel-Sattar Gadallah ${ }^{1,2}$ and M. M. El-Nahass ${ }^{3}$ \\ ${ }^{1}$ Laboratoire de Nanotechnologie et d'Instrumentation Optique, Institut Charles Delaunay, CNRS UMR 6279, \\ Université de Technologie de Troyes, 12 rue Marie Curie, BP 2060, 10010 Troyes Cedex, France \\ ${ }^{2}$ National Institute of Laser Enhanced Science, Laser Sciences and Interactions, Cairo University, Giza 12613, Egypt \\ ${ }^{3}$ Physics Department, Faculty of Education, Ain Shams University, Roxy, Cairo 11757, Egypt \\ Correspondence should be addressed to Abdel-Sattar Gadallah; agadallah@niles.edu.eg
}

Received 8 May 2013; Revised 17 August 2013; Accepted 4 September 2013

Academic Editor: Yuri Galperin

Copyright ( 2013 A.-S. Gadallah and M. M. El-Nahass. This is an open access article distributed under the Creative Commons Attribution License, which permits unrestricted use, distribution, and reproduction in any medium, provided the original work is properly cited.

\begin{abstract}
We report manufacturing and characterization of low cost $\mathrm{ZnO}$ thin films grown on glass substrates by sol-gel spin coating method. For structural properties, X-ray diffraction measurements have been utilized for evaluating the dominant orientation of the thin films. For optical properties, reflectance and transmittance spectrophotometric measurements have been done in the spectral range from $350 \mathrm{~nm}$ to $2000 \mathrm{~nm}$. The transmittance of the prepared thin films is $92.4 \%$ and $88.4 \%$. Determination of the optical constants such as refractive index, absorption coefficient, and dielectric constant in this wavelength range has been evaluated. Further, normal dispersion of the refractive index has been analyzed in terms of single oscillator model of free carrier absorption to estimate the dispersion and oscillation energy. The lattice dielectric constant and the ratio of free carrier concentration to free carrier effective mass have been determined. Moreover, photoluminescence measurements of the thin films in the spectral range from $350 \mathrm{~nm}$ to $900 \mathrm{~nm}$ have been presented. Electrical measurements for resistivity evaluation of the films have been done. An analysis in terms of order-disorder of the material has been presented to provide more consistency in the results.
\end{abstract}

\section{Introduction}

One of the most important wide bandgap oxide semiconductors that draw worldwide attention of researchers is zinc oxide $(\mathrm{ZnO})$ [1]. This unintentional n-type compound with hexagonal (wurtzite) structure possesses unique properties such as high electrochemical stability, resistivity control, transparency in the visible range with a wide bandgap absence of toxicity, abundance in nature, important piezoelectric properties, and high quantum yield. These appealing properties are utilized in a wide range of applications including stimulated emissions with high optical gain and low loss [2], UV detectors [3], solar cells [4], light emitting diodes [5], and gas sensing [6]. Hence, there is continuous motivation to report manufacturing and characterization of $\mathrm{ZnO}$.

More growth methods have been utilized for $\mathrm{ZnO}$ thin films including molecular beam epitaxy [7], metal-organic chemical-vapor deposition [8], pulsed laser deposition [2], radio frequency magnetron sputtering [9], spray pyrolysis
[6], thermal oxidation, and sol-gel spin coating $[10,11]$. Although these methods are used for the preparation of thin films, a simple and economic method, which has high growth rate and mass production capability and suitable for incorporating of foreign impurities (dopants), is generally desirable. Sol-gel spin coating is one of such methods which involves low cost equipments and raw materials. This method is basically a simple technology in which an ionic solutioncontaining the constituent elements of a compound in the form of soluble salts-is spun on the substrate and heated at the crystallization temperature. The polycrystalline $\mathrm{ZnO}$ thin films with c-axis orientation prepared by the sol-gel process depends on the sol concentration, heat-treatment conditions [11], substrates used [12], and film thickness [13].

In this effort, transparent and semiconducting nanocrystalline $\mathrm{ZnO}$ thin films have been grown by low cost solgel spin coating method on glass substrates. Investigations of the effect of the growth parameters such as preheating 


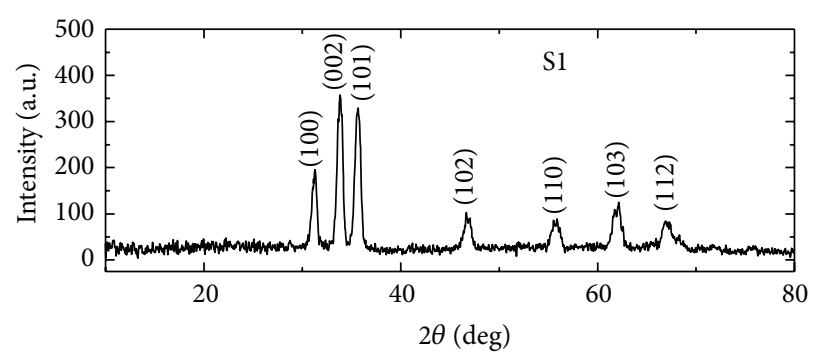

(a)

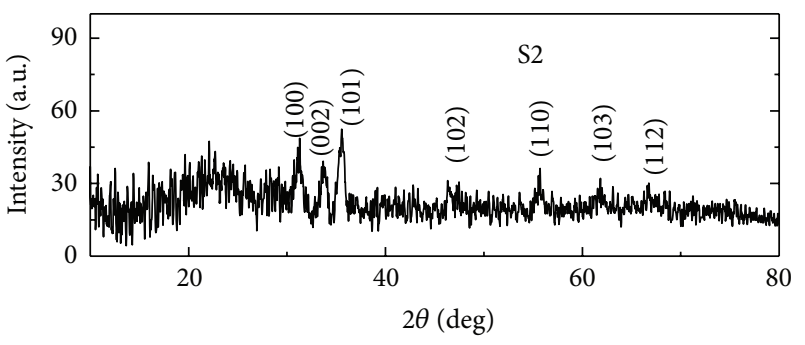

(b)

FIGURE 1: X-ray diffraction (XRD) patterns obtained for ZnO thin films S1 and S2.

temperature, spin speed, initial concentration on the crystallization, optical constants, photoluminescence, and electrical resistivity of $\mathrm{ZnO}$ thin films are presented. In addition, an analysis in terms of order-disorder of the material to provide consistency in the results is reported.

\section{Material and Methods}

Zinc acetate dihydrate, $\left(\mathrm{CH}_{3} \mathrm{COO}\right)_{2} \mathrm{Zn} \cdot 2 \mathrm{H}_{2} \mathrm{O}(\mathrm{ZAD})$, diethanolamine $\left(\mathrm{NH}\left(\mathrm{CH}_{2} \mathrm{CH}_{2} \mathrm{OH}\right)_{2}\right)$, and n-butyl alcohol $\left(\mathrm{C}_{4} \mathrm{H}_{9} \mathrm{OH}\right)$ were purchased from Oxford Laboratory Reagent, Scharlau, and British Drug Houses, respectively. All chemicals have been utilized without further purification. Thin films have been spun on a microscope glass substrates using spin coater, model Spin-1200D, MIDAS system.

The preparation method of $\mathrm{ZnO}$ thin films was reported elsewhere [10]. Namely, ZAD, n-butyl alcohol, and diethanolamine were utilized as a zinc precursor, solvent, and stabilizer, respectively. The concentration of ZAD was $1.3 \mathrm{M}$ and $0.35 \mathrm{M}$ for sample 1 (S1) and sample 2 (S2), respectively. The molar ratio of ZAD to diethanolamine was $1: 1$, and the volume of $\mathrm{n}$-butyl alchohol is $10 \mathrm{~mL}$. The resulting solution was stirred at $70^{\circ} \mathrm{C}$ to form a clear and homogeneous mixture. The transparent sol was left for about $24 \mathrm{~h}$ to allow good adhesion with the substrate. For cleaning the glass substrate, it was rinsed in boiling nitric acid for about 10 minutes and then rinsed in hot acetone and hot isopropanol. Finally, the substrate was rinsed in boiling distilled water. The substrate was then dried for 10 minutes, and it was ready for spin coating process. The coating solution was dropped onto the glass substrate, which was rotated at $3000 \mathrm{rpm}$ for $30 \mathrm{~s}$ for S1 and $4000 \mathrm{rpm}$ for $30 \mathrm{~s}$ for $\mathrm{S} 2 \mathrm{using}$ spin coater. Each as-coated film was heated from room temperature to $300^{\circ} \mathrm{C}$ (at a heating rate of $10^{\circ} \mathrm{C} / \mathrm{min}$ ) and then maintained at $300^{\circ} \mathrm{C}$ for $20 \mathrm{~min}$. This preheating is to evaporate the solvents. These procedures were repeated four times. The samples were then heated at $550^{\circ} \mathrm{C}$ (at a heating rate of $10^{\circ} \mathrm{C} / \mathrm{min}$ ) and then maintained at $550^{\circ} \mathrm{C}$ for $2 \mathrm{~h}$ in a furnace in air ambiance to obtain a crystallized $\mathrm{ZnO}$ thin films.

The ZnO films were characterized by XRD for the structural properties using a Philips (PW1710 BASED) diffractometer. The surface morphology of the $\mathrm{ZnO}$ thin films was measured by scanning electron microscope, model Quanta 250 FEG.

Optical transmittance and reflectance spectra have been recorded by Jasco V-670 double-beam recording spectrophotometer in the range from $350 \mathrm{~nm}$ to $2000 \mathrm{~nm}$. The absolute values of transmittance and reflectance have been calculated from the measured transmittance and reflectance [14-16]. The optical bandgap energy was estimated using an extrapolation of the linear portion of $(\alpha h \nu)^{2}$ versus $h \nu$ where $\alpha$ is the absorption coefficient and $h v$ is the photon energy. For investigating photoluminescence and photoluminescence intensity as a function of the excitation intensity, HeCd laser operating at $325 \mathrm{~nm}$ and third harmonic pulsed Nd:YAG laser at $355 \mathrm{~nm}$ with density filters have been used as excitation sources. The laser beam was directed with an angle of $45^{\circ}$ normal to the surface of the thin film and focused to a $1 \mathrm{~mm}^{2}$ spot. The backscattered emission normal to the surface was collected and focused to a spectrometer, which is coupled to a Peltier-cooled CCD camera. Electrical resistivity has been measured using four-point probe. All measurements have been carried out at room temperature.

\section{Results and Discussion}

3.1. Structural Investigations. Figure 1 shows the XRD results of S1 and S2. Both thin films show polycrystalline with hexagonal structure of $\mathrm{ZnO}$ (JCPDS card 79-0205). However, S1 has the strongest reflection at (002) plane which is the densest plane of this sample. On the other hand, S2 has the strongest reflection at (101), the densest plane of this sample. Reflections for planes (100), (002), (101), (102), (110), (103), and (112) are observed for both samples. Useful information that characterizes the growth is extracted from the XRD measurements. These include the average crystallite size, defect density, lattice strain, and stress. The average crystallite sizes $(D)$ of the films have been calculated using Scherrer equation [17]:

$$
D=\frac{0.94 \lambda}{\beta \cos \theta},
$$

where $\lambda, \beta$, and $\theta$ are X-ray wavelength (1.54 $\AA$ ), full width at half maximum of the diffraction peak, and the diffraction angle. Using (1) and the data obtained from Figure 1, the crystallite sizes of S1 and S2 are $12.8 \mathrm{~nm}$ and $11 \mathrm{~nm}$, respectively. Moreover, the defect density $\delta$, defined as the length of the dislocation line per unit volume, is given by [18]

$$
\delta=\frac{1}{D^{2}} .
$$

Its value for $\mathrm{S} 1$ is $6.13 \times 10^{-3} \mathrm{~nm}^{-2}$ and for S2 is $8.31 \times$ $10^{-3} \mathrm{~nm}^{-2}$. The lower the dislocation density is, the better is 


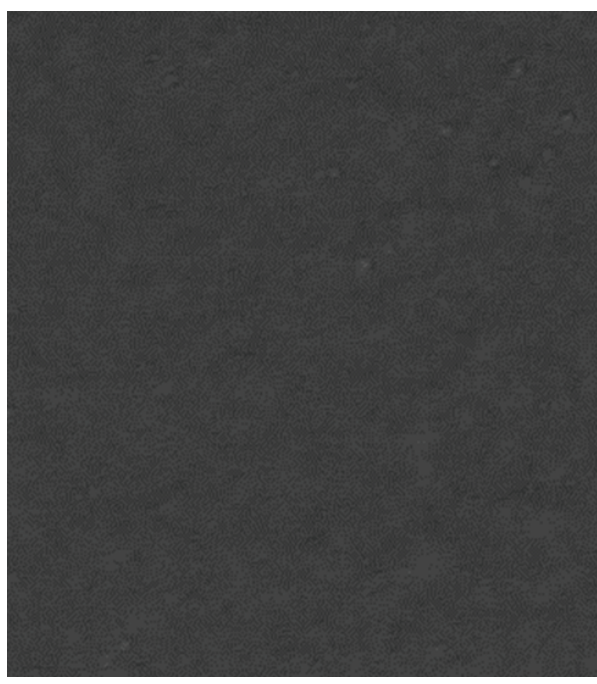

(a)

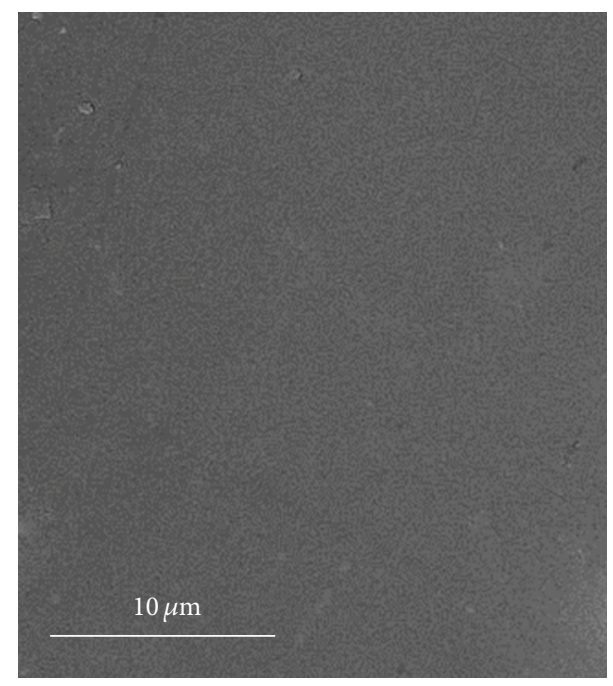

(b)

Figure 2: Top view of $\mathrm{ZnO}$ thin films $\mathrm{S} 1$ and $\mathrm{S} 2 \mathrm{using}$ SEM.

the quality of the crystallized thin film. Further, the lattice strain $\eta$ caused by mismatch between the glass substrate and the $\mathrm{ZnO}$ thin film is given by [19]

$$
\eta=\frac{\beta}{4 \tan \theta} .
$$

This gives a lattice strain of $2.9 \times 10^{-2}$ for $\mathrm{S} 1$ and $3.3 \times 10^{-2}$ for S2. Further, the lattice constants $a=b \neq c$ of the hexagonal structure are given by [17]

$$
a=b=\frac{\lambda}{\sqrt{3} \sin \theta}, \quad c=\frac{\lambda}{\sin \theta} .
$$

The values of $a$ and $c$ for $S 1$ are $3.295 \AA$ and $5.289 \AA$. For S2, they are $3.295 \AA$ and $5.317 \AA$. The standard values of $a$ and $c$ for the hexagonal structure of $\mathrm{ZnO}$ are $3.253 \AA$ and $5.215 \AA$. Hence, these standard values are close to our reported values. The residual stress in the thin film can be determined by [20]

$$
\sigma=-233 \frac{c-c_{0}}{c_{0}}[\mathrm{GPa}],
$$

where $\mathcal{c}_{0}=5.2066 \AA$ is the unstrained lattice constant for bulk $\mathrm{ZnO}$. This gives a residual stress of $-3.68 \mathrm{GPa}$ for $\mathrm{S} 1$ and $-4.94 \mathrm{GPa}$ for $\mathrm{S} 2$. The minus sign indicates that the residual stress is compressive.

3.2. Surface Morphology. Figure 2 shows top view micrographs of S1 and S2 using SEM measurements. It illustrates that both films are packed and continuous without the presence of porosity or voids. In addition, no cracking is observed. The surfaces of S1 and S2 are smooth. These effects are attributed to the fast ramp rate of $10^{\circ} \mathrm{C} / \mathrm{min}$. Such ramp rate produces small fine nuclei and lead to flat or smooth surface.

3.3. Optical Properties. Transmission and reflection spectra from 350 to $2000 \mathrm{~nm}$ of the thin films are shown in Figure 3.

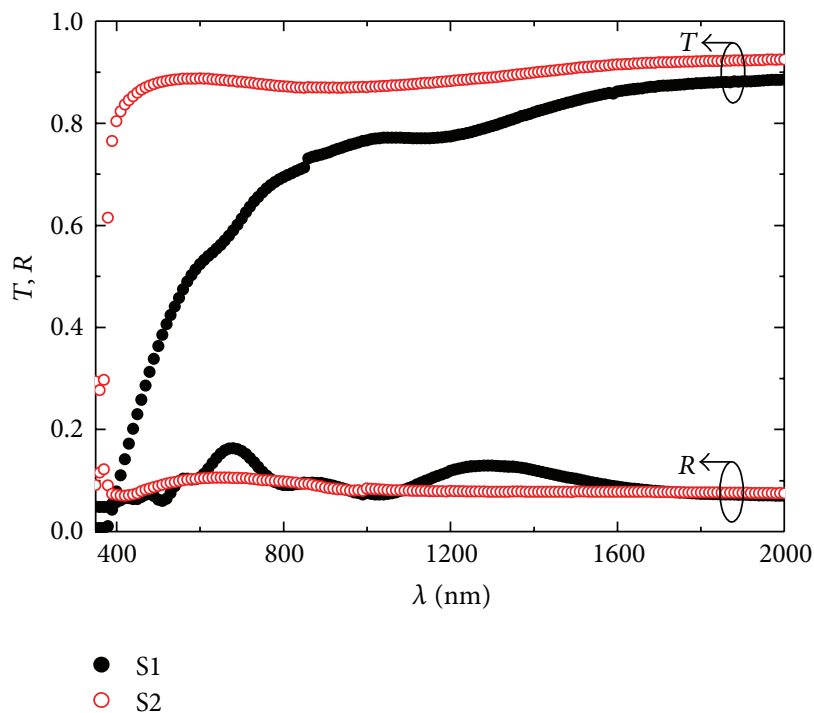

FIGURE 3: Optical transmittance and reflectance spectra obtained for $\mathrm{ZnO}$ thin films S1 and S2.

As the concentration increases from S2 to S1, the transmission decreases. This is attributed to the increase of the roughness of the sample as the concentration increases. This is in agreement with the results published in [21]. The highest transmittance values at $2000 \mathrm{~nm}$ for S2 and S1 are 92.4\% and $88.4 \%$, respectively. S2 has low scattering and thus has higher transmittance than S1. For the reflectivity spectra of S2, it decreases with increasing the wavelength for wavelengths longer than the bandgap transition, which is the normal dispersion of the optical material. In addition, there is a peak in reflectivity near the bandgap wavelength and it is attributed to interband transition from the valence band to the conduction band. For S1, some peaks in the reflectivity curve are observed. Similar behavior is reported in [22]. 


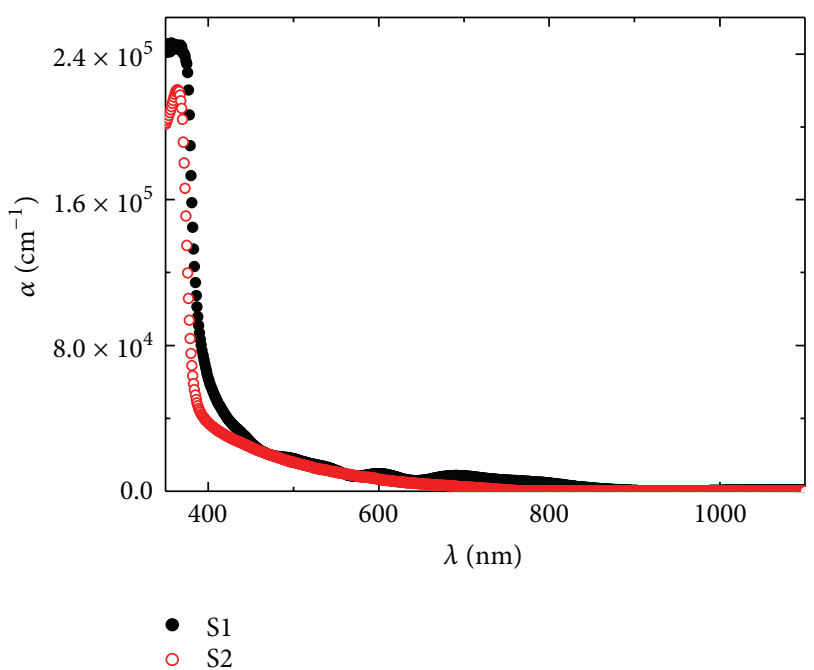

FIgURE 4: Absorption coefficient versus wavelength for $\mathrm{ZnO}$ thin films S1 and S2.

The value of the reflectivity over measured wavelengths for this sample vary from about $5 \%$ to about $17 \%$.

The absorption coefficient is related to the transmittance $T$, the reflectance $R$, and the film thickness $d$ by the following expression [23]:

$$
\alpha=\frac{1}{d} \ln \left[\frac{(1-R)^{2}}{2 T}+\sqrt{\frac{(1-R)^{4}}{4 T^{2}}+R^{2}}\right] .
$$

Figure 4 illustrates the absorption coefficient $\alpha$ for S1 and $\mathrm{S} 2$ in the spectral region from $350 \mathrm{~nm}$ to $1100 \mathrm{~nm}$. The absorption curve can be divided into three regions, namely, strong absorption region for $\lambda \leq 390 \mathrm{~nm}$, absorption tail region near the band edge for $390 \mathrm{~nm}<\lambda<570 \mathrm{~nm}$, and weak absorbing region for wavelengths $>570 \mathrm{~nm}$. In the strong absorption region, an electron in the valence band absorbs certain photon energy and transits to the conduction band leaving a hole in the valence band, that is, formation of exciton. In the absorption tail region, the electron transits to shallow states below the conduction band. Further, the absorption coefficient $\alpha$ is related to the absorbance $A$ in the strong absorption region by Beer-Lambert's law:

$$
\alpha=\frac{2.303}{d} A=\frac{1}{d} \ln \frac{1}{T} .
$$

The film thickness is estimated from cross-sectional view of SEM and is $292 \mathrm{~nm}$ for S1 and $52 \mathrm{~nm}$ for S2. The peak value of the absorption coefficient is about $2.5 \times 10^{5} \mathrm{~cm}^{-1}$ for S1 and $2.2 \times 10^{5} \mathrm{~cm}^{-1}$ for S2. This value is compared to that obtained by pulsed laser deposition and other reported sol-gel technique. In addition, the relation between the absorption coefficient and the incident photon energy $h \nu$ for determination of the optical bandgap $E_{g}$ is given by [24]

$$
\alpha=\frac{B\left(h v-E_{g}\right)^{n / 2}}{h v},
$$

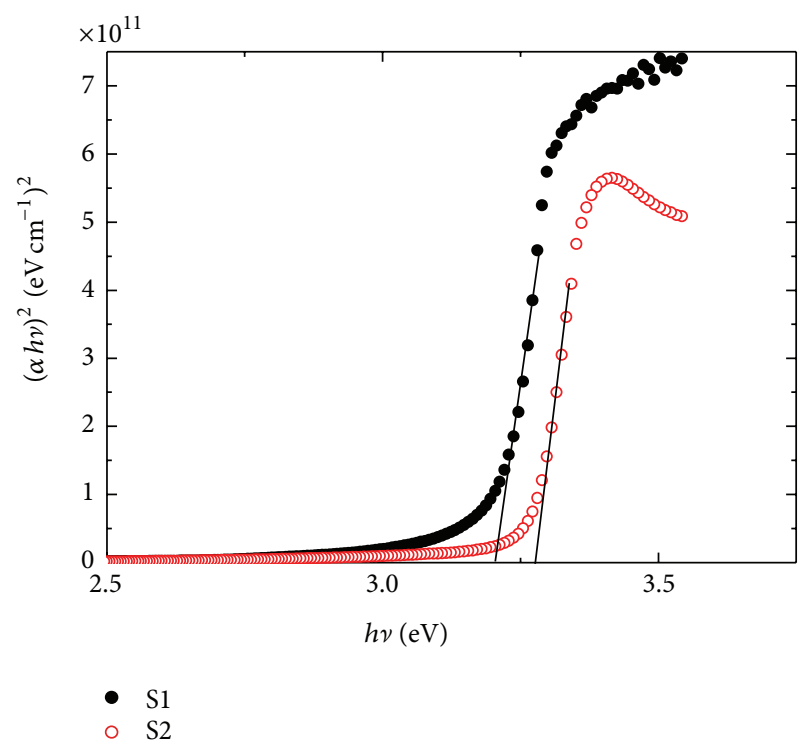

FIGURE 5: Dependence of the $(\alpha h \nu)^{2}$ on the photon energy $(h \nu)$ for $\mathrm{ZnO}$ thin films S1 and S2.

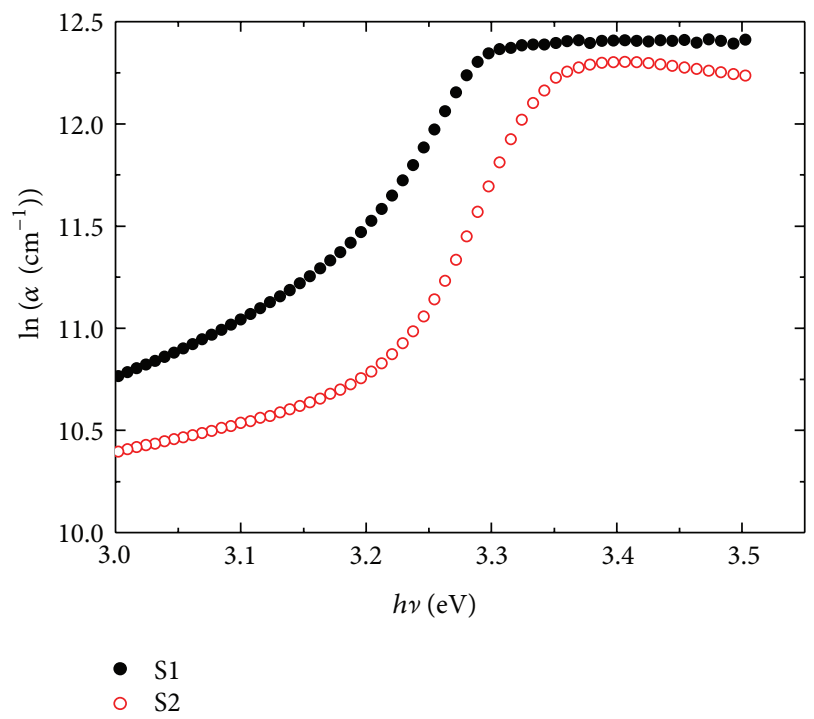

FIgure 6: Dependence of $\ln \alpha$ on $(h \nu)$ for $\mathrm{ZnO}$ thin films S1 and S2.

where $B$ is a constant and $n$ is equal to 1 for direct bandgap material such as $\mathrm{ZnO}$. The constant $B$ depends on the refractive index of the material and the probability of absorption. From the above relationship, the optical bandgap energy $E_{g}$ was estimated. The dependence of $(\alpha h \nu)^{2}$ on $h v$ is presented in Figure 5. From the figure, the value of $E_{g}$ is about $3.2 \mathrm{eV}$ for $\mathrm{S} 1$ and $3.28 \mathrm{eV}$ for S2. This shift in the optical bandgap from S1 to S2 is attributed to the decrease in the crystallite size. This confirms the results evaluated from X-ray diffraction measurements that the crystallite size of S2 is smaller than that of S1.

Figure 6 shows the dependence of the absorption coefficient on the energy of the incident photon near the band edge. 


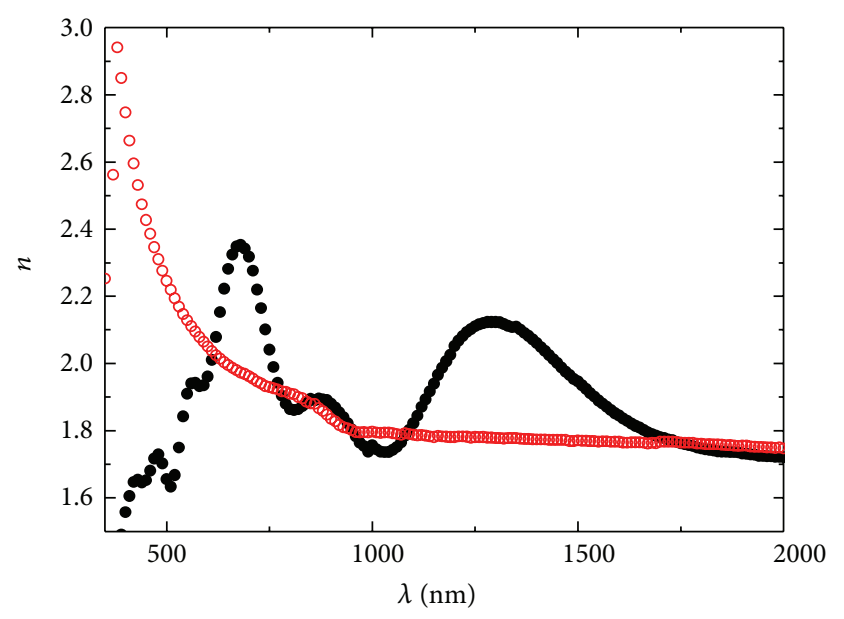

- $\mathrm{S} 1$

○ S2

FIGURE 7: Refractive index versus wavelength for $\mathrm{ZnO}$ thin films S1 and $\mathrm{S} 2$.

Such dependence is governed by Urbach relation, which is [25]

$$
\alpha=\alpha_{0} \exp \left(\frac{h \nu}{E_{u}}\right),
$$

where $\alpha_{0}$ is a constant and $E_{u}$ is the Urbach energy and it corresponds to the width of the band tail or the width of the localized state in the bandgap. Urbach energy can be evaluated from Figure 6 as the reciprocal of the slope in the linear part of the curve. Its value is $101 \mathrm{meV}$ for S1 and $85.4 \mathrm{meV}$ for S2.

The refractive index is related to reflectance, transmittance, and extinction coefficient $k$ by [23]

$$
n=\left(\frac{1+R}{1-R}\right)+\sqrt{\frac{4 R}{(1-R)^{2}}-k^{2}},
$$

where

$$
k=\frac{\alpha \lambda}{4 \pi} .
$$

Figure 7 shows the refractive index of the prepared $\mathrm{ZnO}$ thin films with different growth parameters. S2 has a peak in refractive index at the vicinity of the bandgap transition. The highest value of the refractive index of S2 near the interband transition is around 2.96. At wavelength of $1000 \mathrm{~nm}$, the refractive index of S2 is around 1.8. S1 has anomalous refractive index dependence on wavelength. The highest value of refractive index of S1 is about 2.37 at $680 \mathrm{~nm}$.

Real dielectric constant $\varepsilon_{1}$ as a function of wavelength is shown in Figure 8. For $\mathrm{S} 2$, there is a peak in $\varepsilon_{1}$ near the energy bandgap, which means a strong interaction between photons and electrons at this wavelength. The value of $\varepsilon_{1}$ in the vicinity of the bandgap wavelength for sample S2 is 8.5 . At $2000 \mathrm{~nm}$ the dielectric constant of S1 and S2 approaches the value of 3 to 3.2 .

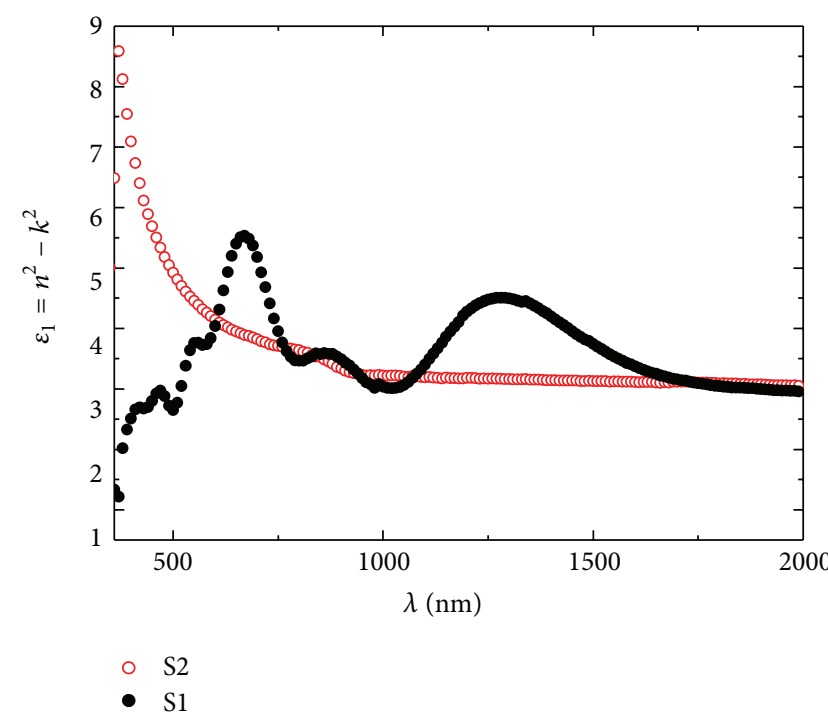

FIGURE 8: Real part of dielectric constant versus wavelength for $\mathrm{ZnO}$ thin films S1 and S2.

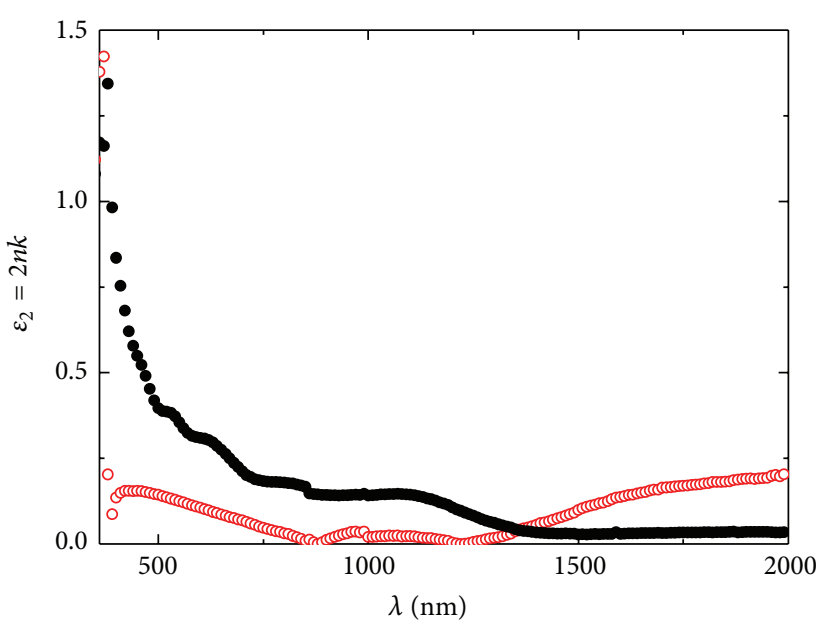

- S2

- S1

FIGURE 9: Imaginary part of dielectric constant versus wavelength for $\mathrm{ZnO}$ thin films S1 and S2.

Imaginary dielectric constant $\varepsilon_{2}$ of the prepared samples as a function of the wavelength is depicted in Figure 9. S2 has the highest value of $\varepsilon_{2}$ at bandgap transition. At longer wavelengths, $\varepsilon_{2}$ gets small for S1 and S2.

The volume energy loss function velf and surface energy loss function self, which are measures for the rate of energy loss of electrons as they traverse the bulk or the surface is plotted for the prepared thin films and depicted in Figure 10. The behavior of velf and self of the samples is similar. The value of velf is higher than that of self at higher energy. S2 with lower sol concentration has lower velf and self compared to S1. For S2, at energy of $3.5 \mathrm{eV}$ the velf is around 0.07 . This value increases to 0.45 for $S 1$ at the same energy. The rate of 


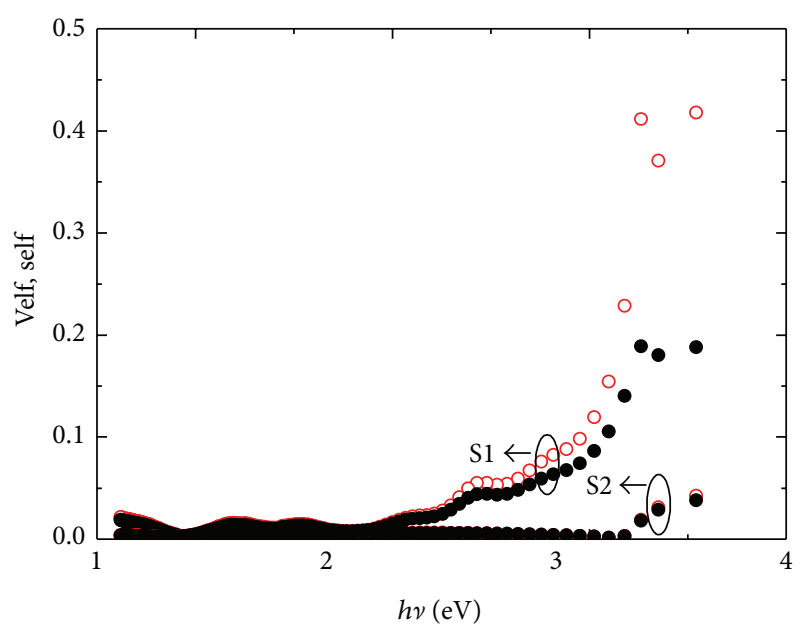

$\circ$ Velf

- Self

FIGURE 10: Volume energy loss function and surface energy loss function versus photon energy for $\mathrm{ZnO}$ thin films S1 and S2.

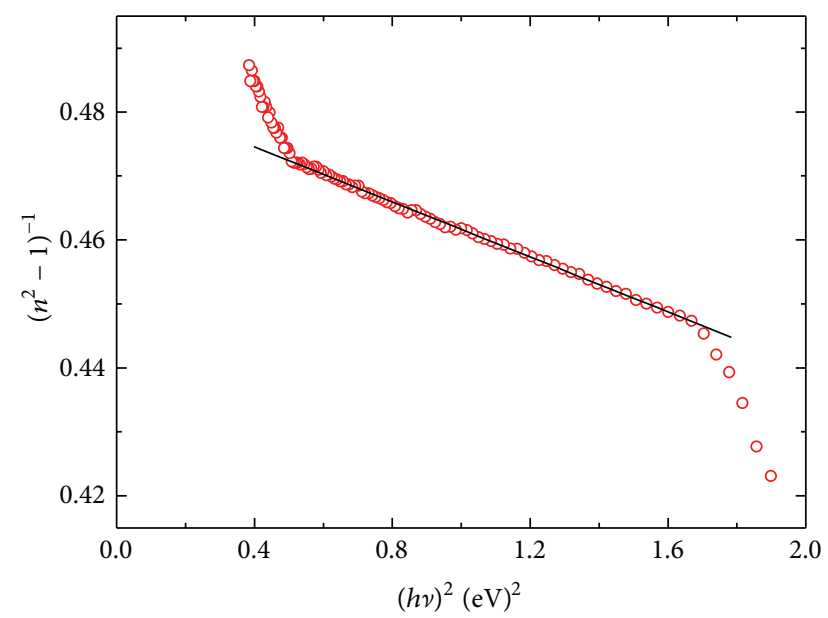

Figure 11: $\left(n^{2}-1\right)^{-1}$ versus $(h \nu)^{2}$ for $\mathrm{ZnO}$ thin films S1 and S2.

energy loss in $\mathrm{S1}$ is thus more than 6 times higher than that of S2.

For S2 at wavelengths longer than the bandgap wavelength, the refractive index decreases with increasing the wavelength. This suggests that the sample shows normal dispersion behavior. Thus, the dispersion data of the refractive index can be analyzed by single oscillator model [26], namely,

$$
\left(n^{2}-1\right)=\frac{E_{d} E_{o}}{E_{o}^{2}-(h \nu)^{2}}
$$

where $E_{d}$ and $E_{o}$ are the dispersion energy and oscillator energy, which are characteristics of the prepared thin films. Experimental verification for the pervious equation can be obtained by plotting $\left(n^{2}-1\right)^{-1}$ versus $(h \nu)^{2}$. Figure 11 shows such plot. It depicts the dielectric response for energies below the optical bandgap. From the intercept of the straight line

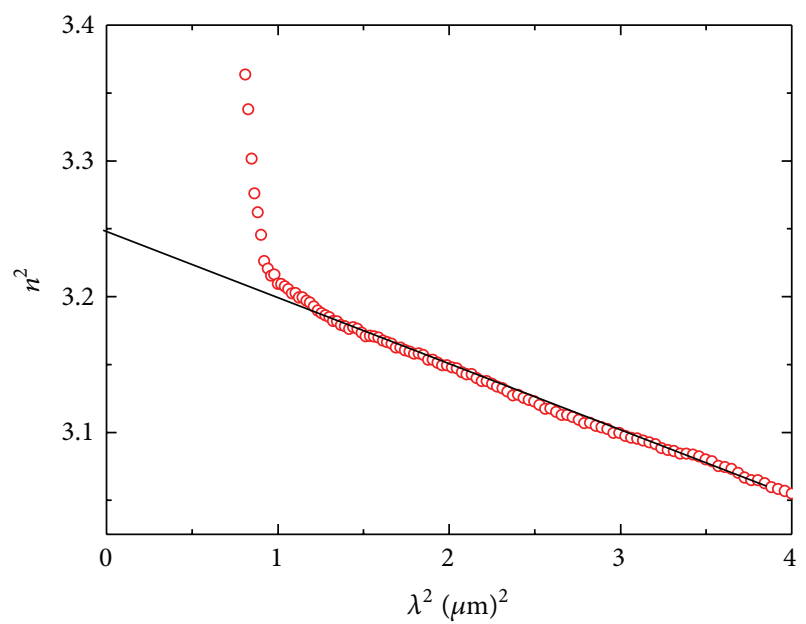

FIGURE 12: $\left(n^{2}\right)$ versus $\lambda^{2}$ for $\mathrm{ZnO}$ thin films S1 and S2.

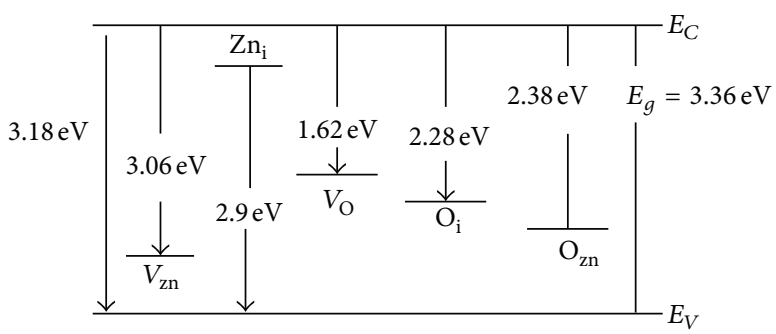

FIGURE 13: Schematic illustration of band structure of $\mathrm{ZnO}$ thin film [28].

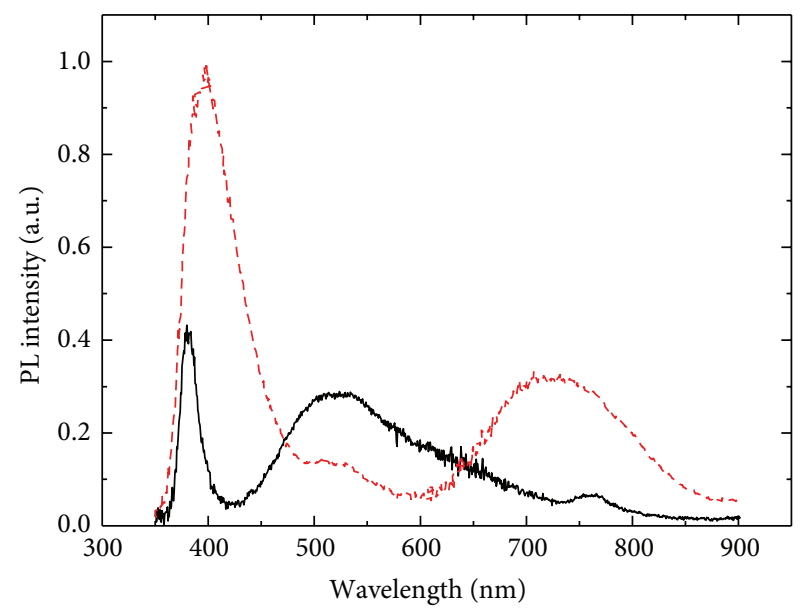

$-\mathrm{S} 1$

$---S 2$

FIGURE 14: Photoluminescence spectra of $\mathrm{ZnO}$ thin films S1 and S2.

with $\left(n^{2}-1\right)^{-1}$ and the slope of the straight line, one can determine the dispersion energy $E_{d}$ and the oscillator energy $E_{o}$. They are $9.7 \mathrm{eV}$ and $4.1 \mathrm{eV}$, respectively. 

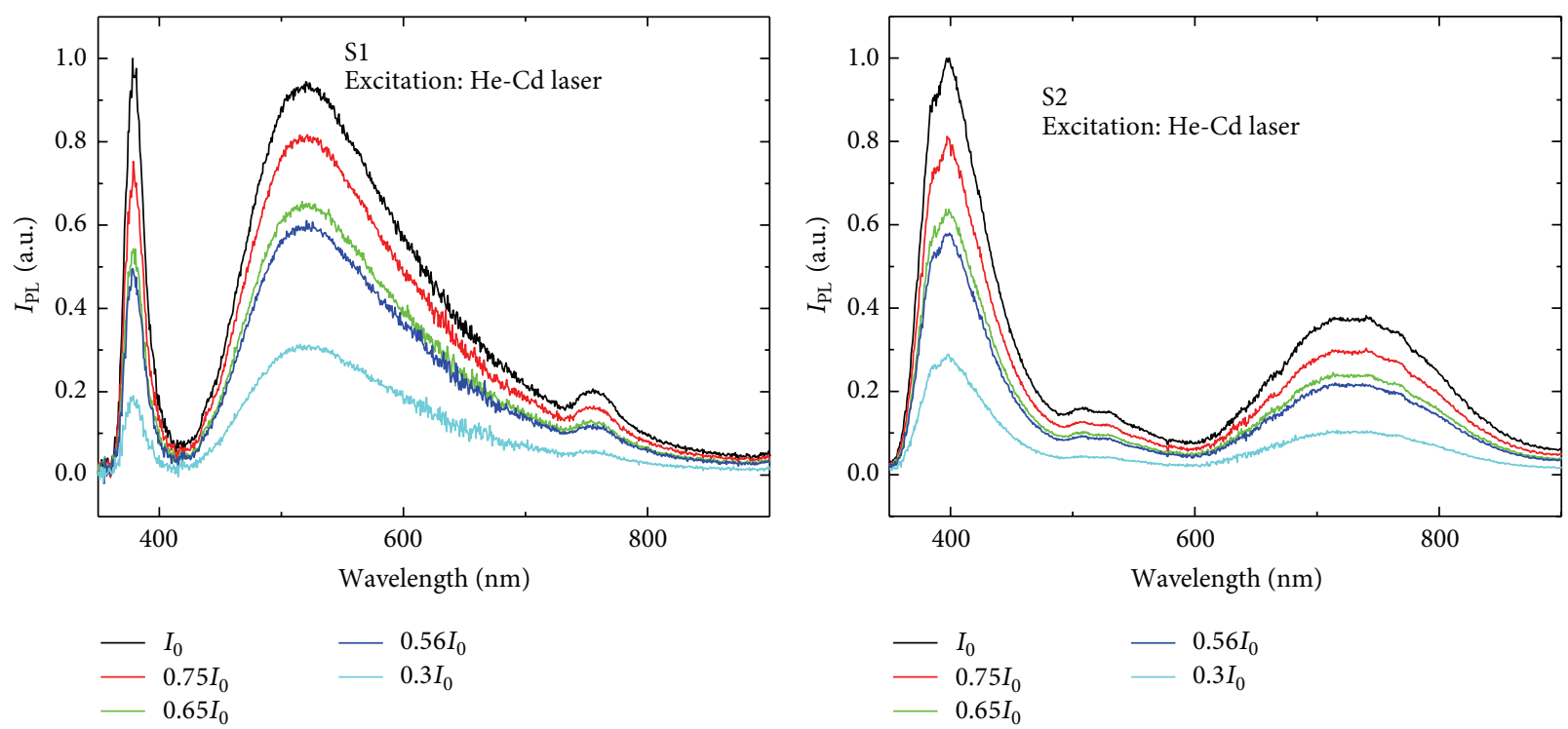

(a)

(b)

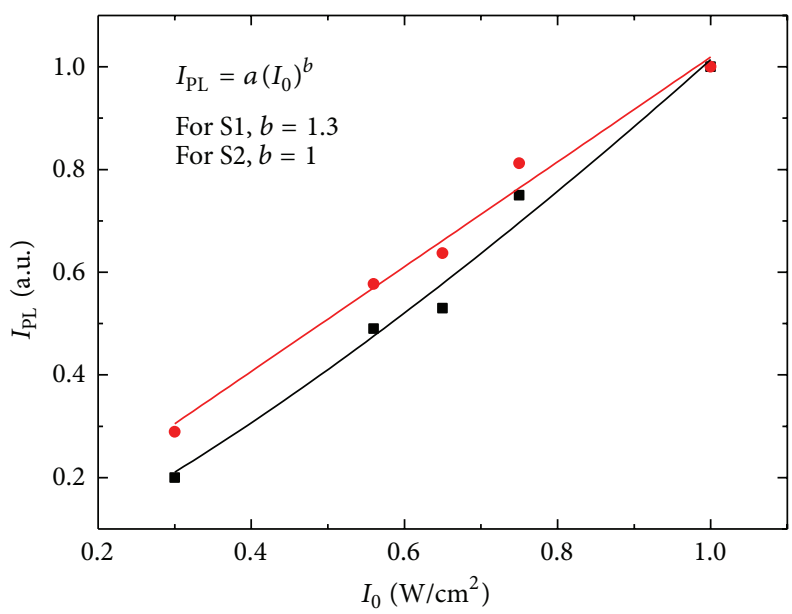

- $\mathrm{S} 1$

- S2

(c)

FIgURE 15: Photoluminescence intensity (a) of S1, (b) of S2, and (c) as a function of excitation intensity. He-Cd laser was used for excitation.

In the weak absorption region, the square of refractive index $n^{2}$ is related to the square of the wavelength $\lambda^{2}$ by the following relation [27]:

$$
n^{2}=\varepsilon_{L}-\frac{e^{2} N}{4 \pi^{2} \varepsilon_{0} m^{*} c^{2}} \lambda^{2}
$$

where $\varepsilon_{L}, \varepsilon_{0}, e, c$, and $N / m^{*}$ are lattice dielectric constant, free space dielectric constant, electron charge, velocity of light, and ratio of free carrier concentration to free carrier effective mass. By plotting relation between $n^{2}$ and $\lambda^{2}$, the lattice dielectric constant and the ratio of $N / m^{*}$ can be obtained. Figure 12 shows this plot. The intercept of the curve with $n^{2}$ axis at zero wavelength gives a lattice dielectric constant of 3.25. Further, the slope of the straight line gives the ratio of $\mathrm{N} / \mathrm{m}^{*}$, which is about $6 \times 10^{46} \mathrm{~cm}^{-3} \mathrm{~g}^{-1}$.
Disordering in $\mathrm{ZnO}$ thin films arises from two main sources, namely, point defects and line defects (also called dislocation). The point defects include oxygen vacancy $V_{O}$, zinc vacancy $V_{\mathrm{zn}}$, oxygen interstitial $\mathrm{O}_{\mathrm{i}}$, zinc interstitial $Z_{\mathrm{i}}$, and antisite oxygen $\mathrm{O}_{\mathrm{zn}}$. These defect states introduce levels inside the bandgap of the material. Figure 13 shows a schematic drawing of the band structure of $\mathrm{ZnO}$ thin film [28]. Three types of transitions can occur in $\mathrm{ZnO}$ thin films with considering these levels into account. These transitions involve interband transition (transition from conduction band to valance band), free to bound transition (transition from valence band to impurity level), and bound to bound transition also called (donor-acceptor pair transition).

Figure 14 illustrates the photoluminescence of the prepared samples with He-Cd laser excitation. For S1, there 


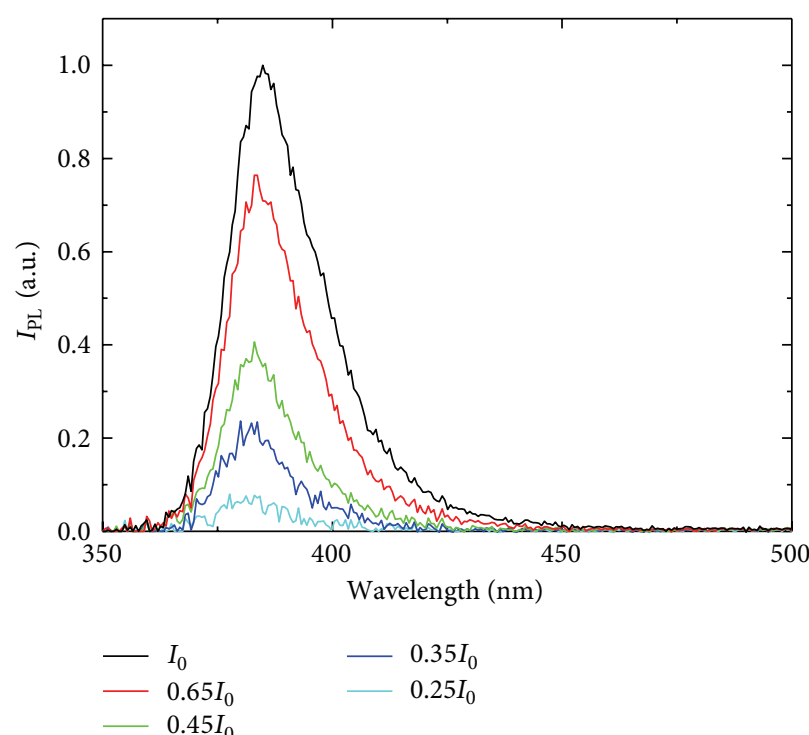

(a)

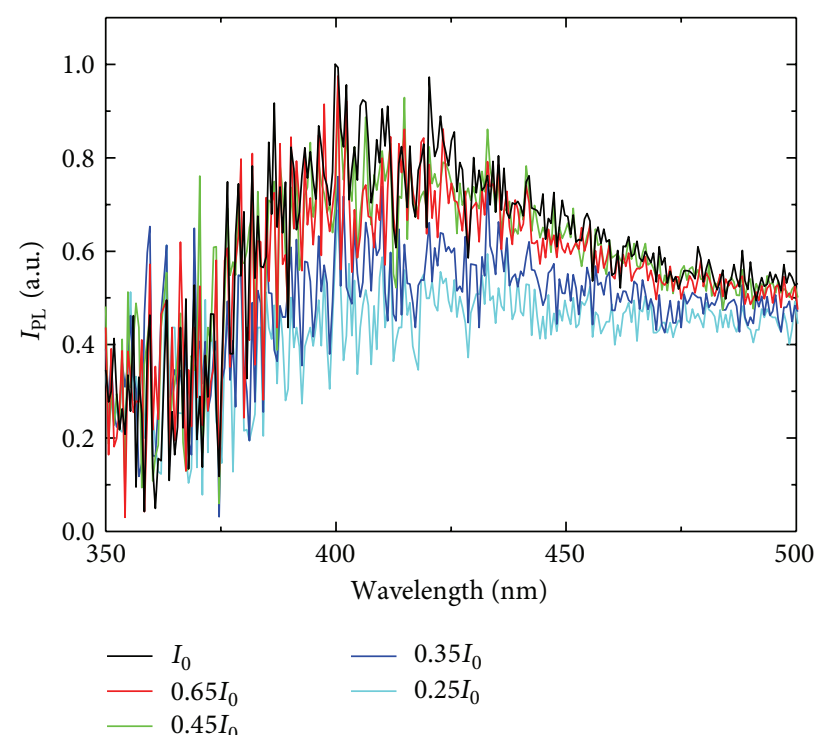

(b)

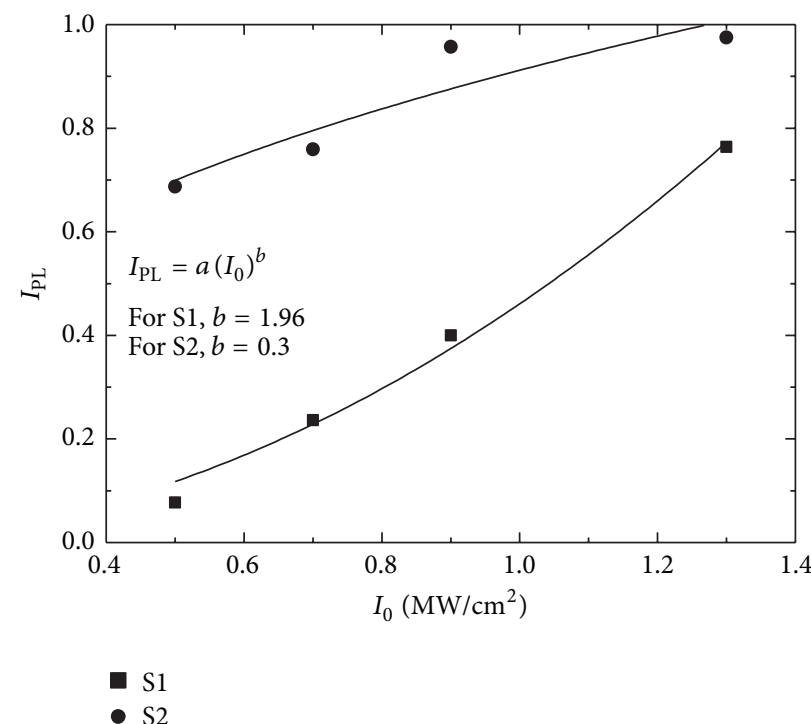

(c)

FIGURE 16: Photoluminescence intensity (a) of S1, (b) of S2, and (c) as a function of excitation intensity. Pulsed third harmonic Nd:YAG laser was used for excitation.

are three bands peaked at around $380 \mathrm{~nm}, 523 \mathrm{~nm}$, and $760 \mathrm{~nm}$. The UV emission at $380 \mathrm{~nm}$ is due to radiative recombination of free exciton [29]. The emission in the green region at $523 \mathrm{~nm}$ is due to transition from the conduction band to oxgen antisite level. The calculated wavelength of this transition using Figure 13 is $521 \mathrm{~nm}$, which matches the experimental result and is consistent with other reported work [28]. The peak at $760 \mathrm{~nm}$ is due to second order diffraction from the grating for the peak at $380 \mathrm{~nm}$. S2 shows three bands peaked at around $398 \mathrm{~nm}, 520 \mathrm{~nm}$, and $730 \mathrm{~nm}$. The violet/blue at $398 \mathrm{~nm}$ could be attributed to donoracceptor pair transition [30], and the green emission centered at about $520 \mathrm{~nm}$ is attributed to transition from conduction band to oxygen antisite level. The broad band centered at around $730 \mathrm{~nm}$ with a full width at half maximum (FWHM) of about $155.5 \mathrm{~nm}$ might be due to transition from conduction band to oxygen vacancy level; we refer to Figure 13.

The variation of photoluminescence from S1 to S2 can be analyzed in terms of order-disorder of the material. S1 shows emission at UV with FWHM of about $20 \mathrm{~nm}$, whereas S2 does not show this band, but it shows emission at the violet/blue band. In fact, the interband UV emission is a measure of the ordering in $\mathrm{ZnO}$, the higher and narrower this band, the better the ordering of the $\mathrm{ZnO}$ thin film. Besides, the violet/blue band in S2 is broad with a FWHM of about $60 \mathrm{~nm}$, and it shows pronounced band shape asymmetry in the low energy side, which is an indication of the disordering in S2 compared to $\mathrm{S} 1$. Further, the photoluminescence intensity was measured as a function of the excitation intensity to explain orderdisorder for both samples at both low excitation regime 


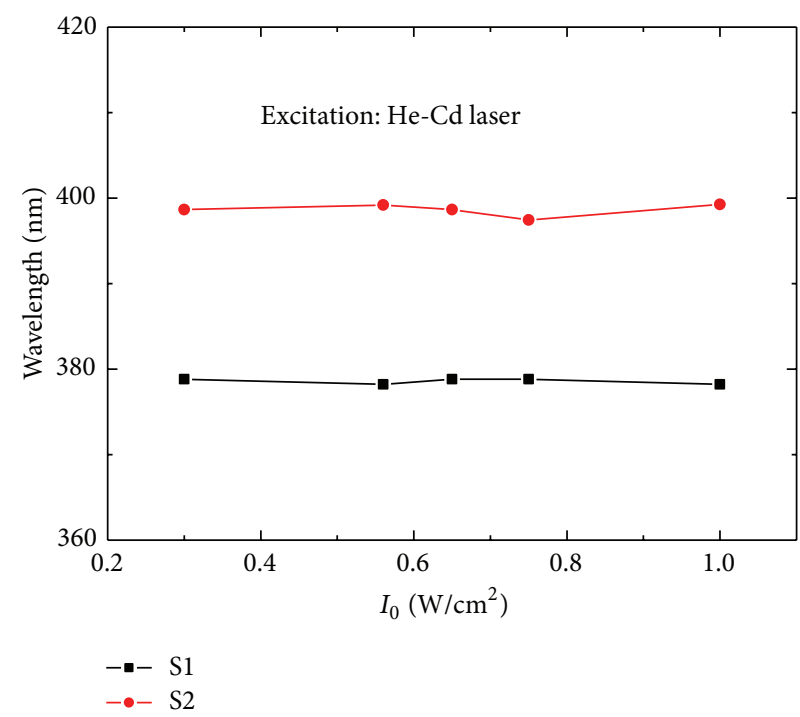

(a)

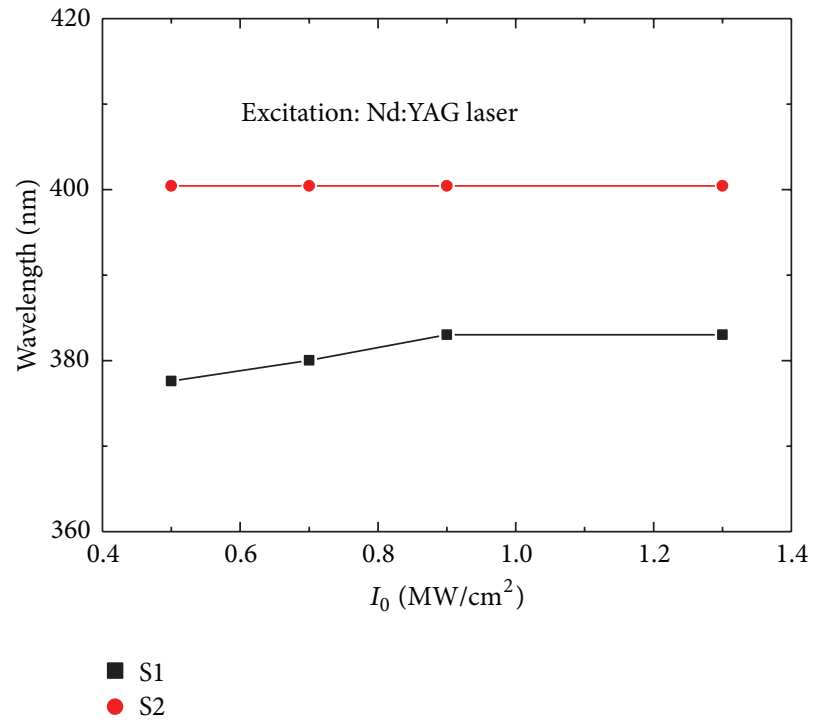

(b)

FIGURE 17: Peak photoluminescence wavelength of S1 and S2 using excitation with (a) He-Cd laser and (b) pulsed third harmonic Nd:YAG laser.

using CW He-Cd laser with power up to $1 \mathrm{~W} / \mathrm{cm}^{2}$ and at high excitation regime using pulsed third harmonic Nd:YAG laser with power up to $1.3 \mathrm{MW} / \mathrm{cm}^{2}$. The photoluminescence intensity $I_{\mathrm{PL}}$ is related to the excitation intensity $I_{0}$ through $[30,31]$

$$
I_{\mathrm{PL}}=a I_{0}^{b}
$$

where $a$ and $b$ are constants. For interband transition, $1<$ $b<2$ and for donor acceptor pair or free to bound transition $b<1$. Figure 15 shows the $I_{\mathrm{PL}}$ with He-Cd laser excitation. While the $I_{\mathrm{PL}}$ at $380 \mathrm{~nm}$ for $\mathrm{S} 1$ shows superlinear dependence on the excitation intensity with $b=1.3$, the $I_{\mathrm{PL}}$ at $398 \mathrm{~nm}$ of S2 shows linear dependence on the excitation intensity. Further, Figure 16 shows $I_{\mathrm{PL}}$ with pulsed laser excitation. In this case, $I_{\mathrm{PL}}$ of UV band at $380 \mathrm{~nm}$ of $\mathrm{S} 1$ shows superlinear dependence on the excitation intensity with $b=1.9$, while $I_{\mathrm{PL}}$ at violet/blue band of S2 shows power dependence with $b=$ 0.3 . Such power dependence agrees well with the literature, (14). S1 shows a variation of the peak photoluminescence wavelength of about $0.6 \mathrm{~nm}$ in low excitation and $6.7 \mathrm{~nm}$ in high excitation intensity as illustrated in Figure 17. Such red shift of about $6.7 \mathrm{~nm}$ is attributed to bandgap renormalization [32]. S2, on the other hand, shows a variation on the peak photoluminescence wavelength of about $1.8 \mathrm{~nm}$ using low excitation and $0.6 \mathrm{~nm}$ using high excitation intensity.

For electrical measurements of the films, the resistivity $\rho$ of S1 was measured using four-point probe. According to this method the resistivity is related to the film thickness $w$, the voltage $V$, and the current $I$ through [33]

$$
\rho=\frac{V}{I} w \frac{\pi}{\ln 2}
$$

Figure 18 shows the $I-V$ curve of $S 1$, from which the slope is obtained to evaluate the resistivity. It was found to be

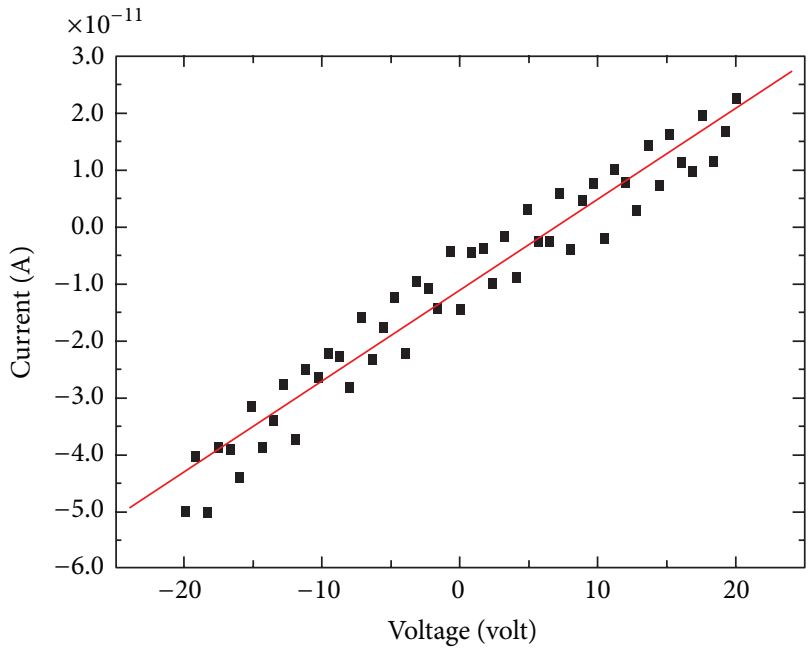

FIGURE 18: Measured $I$ - $V$ curve of S1 for calculating the resistivity of the film.

$82 \mathrm{M} \Omega \mathrm{cm}$. For S2, the current was too low to be measured by the instrument. The low current arises from the disorder that occurs in S2, which is consistent with the results of photoluminescence and X-ray diffraction. Enhancing the electrical properties of these films is a future prospect by enhancing ordering or by intentional doping of the material.

\section{Conclusions}

Growth of $\mathrm{ZnO}$ nanocrystalline thin films has been prepared by sol-gel method. Different preparation parameters such as initial zinc concentration, spin speed, and heating rate have been changed to obtain different properties of $\mathrm{ZnO}$ thin films. 
Structural characterization using X-ray diffraction for the samples has been reported. The transmittance of the thin films is $92.4 \%$ and $88.4 \%$ which is relatively high. Optical bandgap of the prepared samples has been estimated, and it varied from 3.2 to $3.28 \mathrm{eV}$. Real and imaginary dielectric constants of the samples have been reported. Using single oscillator model, the oscillation energy and the dispersion energy of the thin films have been reported, and they were found to be $4.1 \mathrm{eV}$ and $9.7 \mathrm{eV}$, respectively. Velf and self of the prepared samples have been reported as a function of energy. They increase with increasing the initial zinc concentration. Photoluminescence measurements in the range from $350 \mathrm{~nm}$ to $900 \mathrm{~nm}$ have been investigated. Electrical resistivity for the films has been measured and explained. An analysis in terms of order-disorder of the material has been presented to provide more consistency in the results. It is believed that the low cost method of preparation and tuning the properties of the films is crucial in advancement of $\mathrm{ZnO}$ in different fields.

\section{Acknowledgment}

Abdel-Sattar Gadallah would like to thank G. Lérondel and Campus France for photoluminescence measurements and financial support, respectively.

\section{References}

[1] Ü. Özgür, D. Hofstetter, and H. Morkoc, "ZnO devices and applications: a review of current status and future prospects," Proceedings of the IEEE, vol. 98, pp. 1255-1268, 2010.

[2] A.-S. Gadallah, K. Nomenyo, C. Couteau, D. J. Rogers, and G. Lérondel, "Stimulated emission from $\mathrm{ZnO}$ thin films with high optical gain and low loss," Applied Physics Letters, vol. 102, no. 17, Article ID 171105, 4 pages, 2013.

[3] M. G. Ali, S. Singh, and P. Chakrabarti, "Ultraviolet $\mathrm{ZnO}$ photodetectors with high gain," Journal of Electronic Science and Technology, vol. 8, pp. 55-59, 2010.

[4] Y.-H. Lin, P.-C. Yang, J.-S. Huang et al., "High-efficiency inverted polymer solar cells with solution-processed metal oxides," Solar Energy Materials and Solar Cells, vol. 95, no. 8, pp. 2511-2515, 2011.

[5] L. J. Mandalapu, Z. Yang, S. Chu, and J. L. Liu, "Ultraviolet emission from $\mathrm{Sb}$-doped p-type $\mathrm{ZnO}$ based heterojunction lightemitting diodes," Applied Physics Letters, vol. 92, no. 12, Article ID 122101, 3 pages, 2008.

[6] S. S. Badadhe and I. S. Mulla, "Effect of aluminium doping on structural and gas sensing properties of zinc oxide thin films deposited by spray pyrolysis," Sensors and Actuators B, vol. 156, no. 2, pp. 943-948, 2011.

[7] Y. W. Heo, D. P. Norton, and S. J. Pearton, "Origin of green luminescence in $\mathrm{ZnO}$ thin film grown by molecular-beam epitaxy," Journal of Applied Physics, vol. 98, no. 7, Article ID 073502, 6 pages, 2005.

[8] S. T. Tan, B. J. Chen, X. W. Sun et al., "Blueshift of optical band gap in $\mathrm{ZnO}$ thin films grown by metal-organic chemical-vapor deposition," Journal of Applied Physics, vol. 98, no. 1, Article ID 013505, 5 pages, 2005.

[9] Q. P. Wang, X. J. Zhang, C. Q. Wang, S. H. Chen, X. H. Wu, and H. L. Ma, "Influence of excitation light wavelength on the photoluminescence properties for $\mathrm{ZnO}$ films prepared by magnetron sputtering," Applied Surface Science, vol. 254, no. 16, pp. 5100-5104, 2008.

[10] K. C. Kim, E. K. Kim, and Y. S. Kim, "Growth and physical properties of sol-gel derived Co doped $\mathrm{ZnO}$ thin film," Superlattices and Microstructures, vol. 42, pp. 246-250, 2007.

[11] Y. Kim, W. Tai, and S. Shu, "Effect of preheating temperature on structural and optical properties of $\mathrm{ZnO}$ thin films by sol-gel process," Thin Solid Films, vol. 491, no. 1-2, pp. 153-160, 2005.

[12] S. Chakrabarti, D. Ganguli, and S. Chaudhuri, "Substrate dependence of preferred orientation in sol-gel-derived zinc oxide films," Materials Letters, vol. 58, no. 30, pp. 3952-3957, 2004.

[13] M. H. Aslan, A. Y. Oral, E. Menşur, A. Gül, and E. Basşaran, "Preparation of C-axis-oriented zinc-oxide thin films and the study of their microstructure and optical properties," Solar Energy Materials and Solar Cells, vol. 82, pp. 543-552, 2004.

[14] M. M. El-Nahass, "Optical properties of tin diselenide films," Journal of Materials Science, vol. 27, no. 24, pp. 6597-6604, 1992.

[15] A. M. Bakry and A. H. El-Naggar, "Doping effects on the optical properties of evaporated a-Si:H films," Thin Solid Films, vol. 360, no. 1-2, pp. 293-297, 2000.

[16] H. Murmann, "Der spektrale Verlauf der anomalen optischen Konstanten dünnen Silbers," Zeitschrift für Physik, vol. 101, no. 9-10, pp. 643-648, 1936.

[17] B. D. Cullity and S. Rstock, Elements of X-Ray Diffraction, Prentice Hall, New Jersey, NJ, USA, 2001.

[18] G. B. Williamson and R. C. Smallman, "Dislocation densities in some annealed and cold-worked metals from measurements on the X-ray debye-scherrer spectrum," Philosophical Magazine, vol. 1, no. 1, pp. 34-46, 1956.

[19] H. P. Klug and L. E. Alexander, X-Ray Diffraction Procedures for Polycrystalline and Amorphous Materials, Wiley, New York, NY, USA, 1974.

[20] Y. G. Wang, S. P. Lau, H. W. Lee et al., "Comprehensive study of $\mathrm{ZnO}$ films prepared by filtered cathodic vacuum arc at room temperature," Journal of Applied Physics, vol. 94, no. 3, pp. 15971604, 2003.

[21] S. O'Brien, L. H. K. Koh, and G. M. Crean, "ZnO thin films prepared by a single step sol-gel process," Thin Solid Films, vol. 516, no. 7, pp. 1391-1395, 2008.

[22] C. E. Benouis, A. Sanchez-Juarez, and M. S. Aida, "Physics properties comparison between undoped $\mathrm{ZnO}$ and $\mathrm{AZO}$, IZO doped thin films prepared by spray pyrolysis," Journal of Applied Sciences, vol. 7, no. 2, pp. 220-225, 2007.

[23] M. Di Giulio, G. Miccci, R. Rella, P. Siciliano, and A. Tepore, "Optical absorption of tellurium suboxide thin films," Physica Status Solidi A, vol. 136, pp. K101-K104, 1993.

[24] J. Tauc, Amorphous and Liquid Semiconductors, Plenum, London, UK, 1974.

[25] F. Urbach, "The long-wavelength edge of photographic sensitivity and of the electronic absorption of solids," Physical Review, vol. 92 , no. 5, pp. 1324-1324, 1953.

[26] S. H. Wemple and M. DiDomenico, "Behavior of the electronic dielectric constant in covalent and ionic materials," Physical Review B, vol. 3, no. 4, pp. 1338-1351, 1971.

[27] P. O. Edward, Handbook of Optical Constants of Solids, Academic Press, New York, NY, USA, 1985.

[28] B. Lin, Z. Fu, and Y. Jia, "Green luminescent center in undoped zinc oxide films deposited on silicon substrates," Applied Physics Letters, vol. 79, no. 7, p. 943, 2001. 
[29] X. Q. Zhang, I. Suemune, H. Kumano, J. Wang, and S. H. Huang, "Surface-emitting stimulated emission in high-quality ZnO thin films," Journal of Applied Physics, vol. 96, no. 7, pp. 3733-3736, 2004.

[30] M. Peres, S. Magalhães, M. R. Soares et al., "Disorder induced violet/blue luminescence in rf-deposited $\mathrm{ZnO}$ films," Physica Status Solidi C, vol. 10, no. 4, pp. 662-666, 2013.

[31] T. Schmidt, K. Lischka, and W. Zulehner, "Excitation-power dependence of the near-band-edge photoluminescence of semiconductors," Physical Review B, vol. 45, no. 16, pp. 8989-8994, 1992.

[32] D. M. Bagnall, Y. F. Chen, Z. Zhu, T. Yao, M. Y. Shen, and T. Goto, "High temperature excitonic stimulated emission from ZnO epitaxial layers," Applied Physics Letters, vol. 73, no. 8, pp. 1038-1040, 1998.

[33] F. M. Smits, "Measurement of sheet resistivities with the fourpoint probe," Bell System Technical Journal, vol. 37, no. 3, pp. 711$718,1958$. 

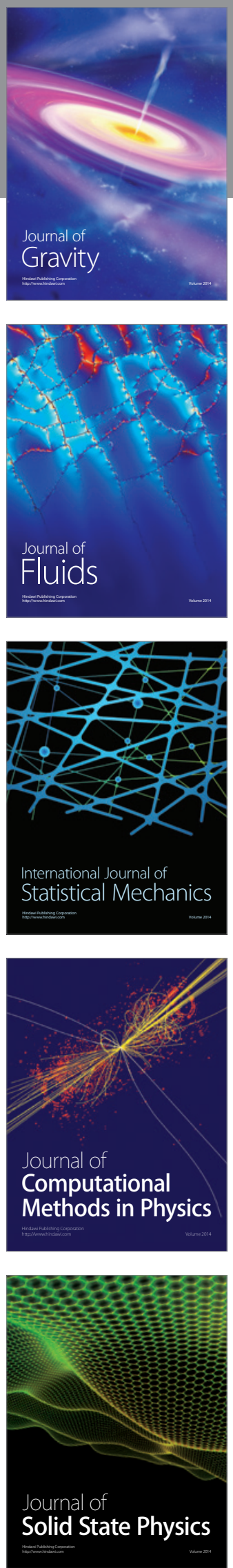

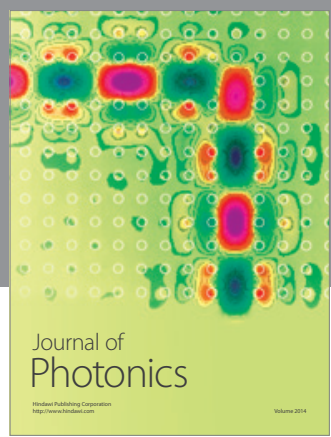

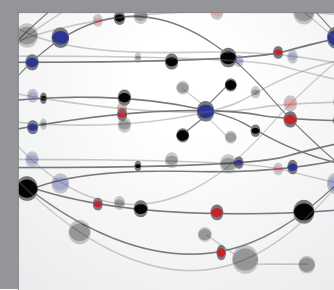

The Scientific World Journal

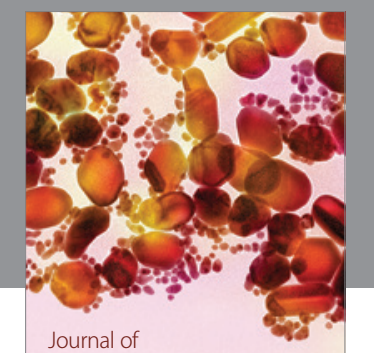

Soft Matter
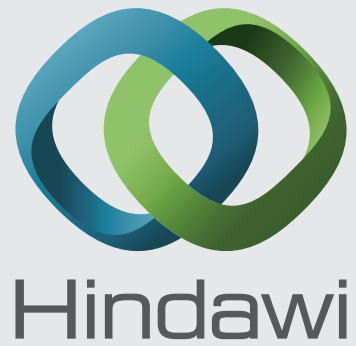

Submit your manuscripts at

http://www.hindawi.com
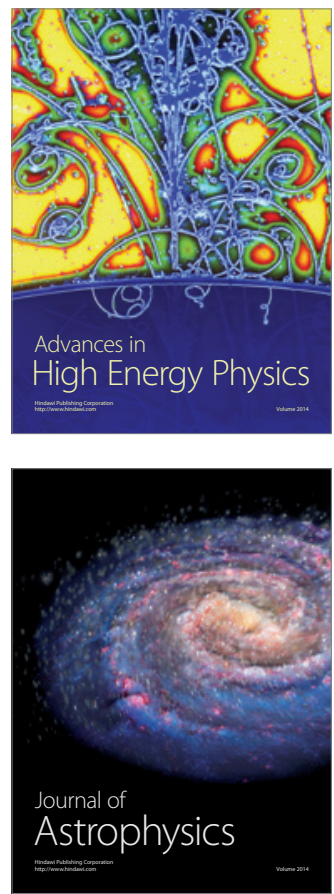
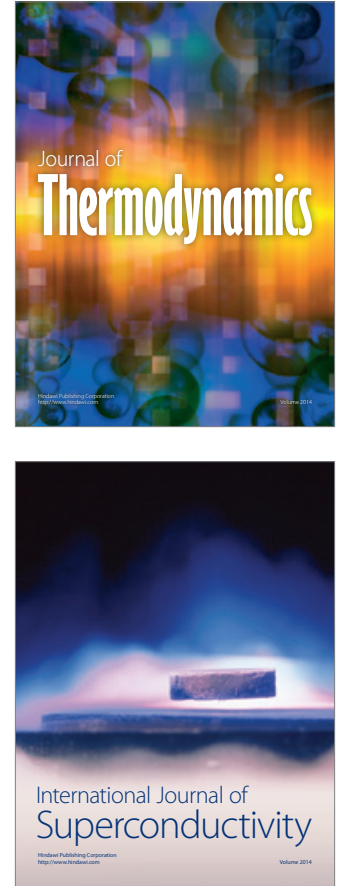
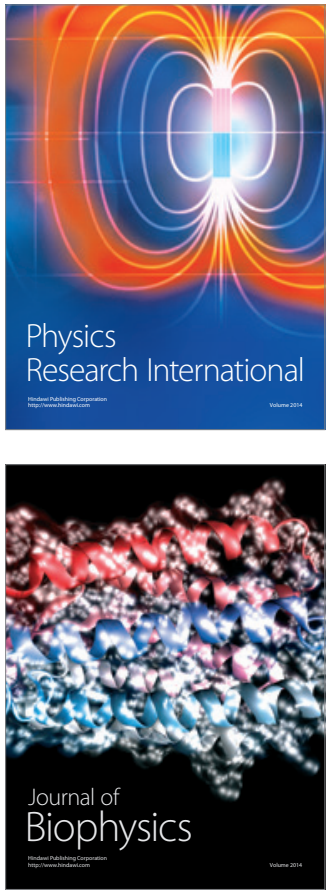
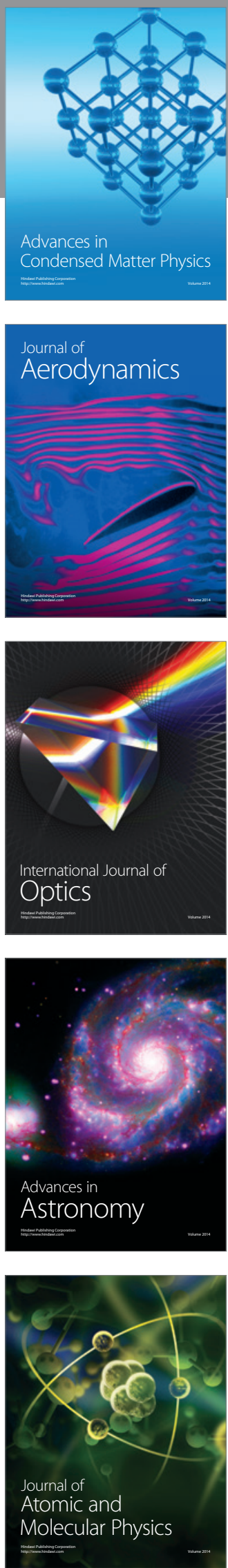